\title{
Toxicity and cellular uptake of gold nanoparticles: what we have learned so far?
}

\author{
Alaaldin M. Alkilany • Catherine J. Murphy
}

Received: 6 November 2009/Accepted: 20 March 2010/Published online: 6 April 2010

(C) Springer Science+Business Media B.V. 2010

\begin{abstract}
Gold nanoparticles have attracted enormous scientific and technological interest due to their ease of synthesis, chemical stability, and unique optical properties. Proof-of-concept studies demonstrate their biomedical applications in chemical sensing, biological imaging, drug delivery, and cancer treatment. Knowledge about their potential toxicity and health impact is essential before these nanomaterials can be used in real clinical settings. Furthermore, the underlying interactions of these nanomaterials with physiological fluids is a key feature of understanding their biological impact, and these interactions can perhaps be exploited to mitigate unwanted toxic effects. In this Perspective we discuss recent results that address the toxicity of gold nanoparticles both in vitro and in vivo, and we provide some experimental recommendations for future research at the interface of nanotechnology and biological systems.
\end{abstract}

Keywords Gold nanoparticles .

Nanoparticle toxicity - Cellular uptake . Pharmacokinetics - Nanotechnology safety · Environment · Exposure

A. M. Alkilany · C. J. Murphy ( $\varangle)$

Department of Chemistry, University of Illinois at Urbana-Champaign, Urbana, IL 61801, USA

e-mail: murphycj@illinois.edu

A. M. Alkilany

e-mail: alkilan1@illinois.edu

\section{Introduction}

Since the early 1990s, enormous efforts worldwide have led to the production of many types of nanomaterials (Alivisatos 1996; Tervonen et al. 2009). The interest in nanomaterials is a result of the extreme dependence of properties (electronic, magnetic, optical, mechanical, etc.) on particle size and shape in the 1-100 $\mathrm{nm}$ regime. These interesting new properties at the nanoscale are the basis of the nanomaterial various applications. The 1-100 nm scale is of interest for biological interfaces; for example, objects less than $12 \mathrm{~nm}$ in diameter may cross the blood-brain barrier (Oberdorster et al. 2004; Sarin et al. 2008; Sonavane et al. 2008), and objects of $30 \mathrm{~nm}$ or less can be endocytosed by cells (Conner and Schmid 2003). With these traits in mind it is not surprising that the biomedical applications of nanomaterials have been increasingly studied (Ferrari 2005; Rosi and Mirkin 2005; Han et al. 2007; Jain et al. 2008; Murphy et al. 2008b).

However, the impact of these nanomaterials on human and environmental health remains unclear (Colvin 2003; Maynard et al. 2006; Nel et al. 2006; Helmus 2007). An increasing number of scientific reports have appeared in the last decade that highlight this issue, with the goal of understanding the interactions between different types of nanoparticles and cells as functions of size, shape, and surface chemistry of the nanomaterial (Lewinski et al. 2008). Unfortunately, no simple conclusions have emerged 
from the available studies due to the variability of parameters such as the physical and chemical properties of the particle, cell type, dosing parameters, and the biochemical assays used. Moreover, the majority of the scientific reports that investigate the cellular impact of nanomaterials are in vitro, with far less effort to understand the real situation in vivo (Fischer and Chan 2007).

The "nanotoxicity" of different nanomaterials has been a subject of excellent available reviews/perspectives (Colvin 2003; Maynard et al. 2006; Nel et al. 2006; Helmus 2007; Lewinski et al. 2008). In order to focus this Perspective, we highlight one chemical type of nanoparticle: gold. Bulk gold is well known to be "safe" and chemically inert, and goldbased compounds have been used in the clinic as antiinflammatory agents to treat rheumatoid arthritis (Auranofin $^{\circledR}$ and Tauredon ${ }^{\circledR}$ ) (Finkelstein et al. 1976). Furthermore, radioactive gold microparticles have been effectively used in local radioisotope cancer therapy (Metz et al. 1982). Nanoscale gold particles show great potential as photothermal therapy agents and as imaging agents in living systems, as will be described below. In most of these imaging and therapeutic applications, the gold particles are $\sim 5 \mathrm{~nm}$ or larger. At sizes larger than $\sim 5 \mathrm{~nm}$, the general assumption is that gold is chemically inert like the bulk. However, the chemical reactivity of gold particles for diameters less than $3 \mathrm{~nm}$ is most likely different than both organogold complexes (Turner et al. 2008) and larger gold nanoparticles (Tsoli et al. 2005). In this paper we review the very recent research in the area of cytotoxicity and biological uptake for gold nanoparticles.

Gold plasmonic properties: the basis of their biomedical applications

Bulk gold is, of course, gold in color. But gold at the nanoscale can appear red, blue, green, or brown (Fig. 1). These colors arise as a result from interaction of conduction band electrons in the metallic nanoparticles with the electric field vector of the incident light. Depending on the gold nanoparticle's size, shape, and surrounding medium, a relatively narrow range of frequencies of incident light induce resonant conduction band electron oscillation. This resonance is called the localized surface plasmon resonance (LSPR), which occurs in the visible and near-infrared regime of the spectrum for gold nanoparticles, depending on their shape and size (Kelly et al. 2003). When the wavelength of light is optimum to satisfy the LSPR, extinction (sum of absorption and scattering) is observed from the nanoparticle. In the case of spherical nanoparticles, a single "plasmon" band is observed in the visible region. But, when the nanoparticles have an anisotropic shape such as a rod, two plasmon bands occur as a result of electron oscillation along the two axes (Fig. 1). The "transverse" plasmon band of gold nanorods occurs at $\sim 520 \mathrm{~nm}$, corresponding to electron oscillation along the short axis of the particle; the "longitudinal" plasmon band at longer wavelengths is governed by the nanorods' length/ width ratio (aspect ratio). The wavelength of the longitudinal band can be tuned by controlling the dimensions of the gold nanorods (Fig. 1).

The dependence of the plasmon band position on the gold nanorod dimensions, and the synthetic ability to control nanorod dimensions, makes it possible to prepare nanoparticles which absorb in the biological "water window" of 800-1200 nm. In this wavelength range, few chromophores absorb, background fluorescence is low, water does not absorb, and thus light can penetrate deeper in biological tissues (Weissleder 2001). These properties are of clinical significance and contribute to the popularity of gold nanorods and other anisotropic shapes for biomedical therapeutic/imaging agents (Jain et al. 2008; Lal et al. 2008; Murphy et al. 2008b; Skrabalak et al. 2008).

The strong light extinction (absorption and scattering) of gold nanorods has been employed in various biomedical imaging applications. For example, strong optical absorption of gold nanorods (at $\lambda=757 \mathrm{~nm}$ ) was used to detect them in mouse tissue (4 $\mathrm{cm}$ depth) using an optoacoustic method (Eghtedari et al. 2007). In our own work, we took advantage of the strong elastic light scattering properties of gold nanorods to measure strain generated by cardiac fibroblast cells in collagen thin films (Stone et al. 2007).

Furthermore, the dependence of the plasmon band position on the degree of aggregation of the nanoparticles and on the dielectric constant of the local environment forms the basis for chemical sensing with gold nanoparticles. The presence of chemical or biological analytes can induce aggregation, disaggregation, or change the local refractive index, which 
Fig. 1 Gold nanorods of different aspect ratios have different colors and tunable ultraviolet-visible-nearinfrared spectra. Scale bars in the transmission electron micrographs at the top are $100 \mathrm{~nm}$

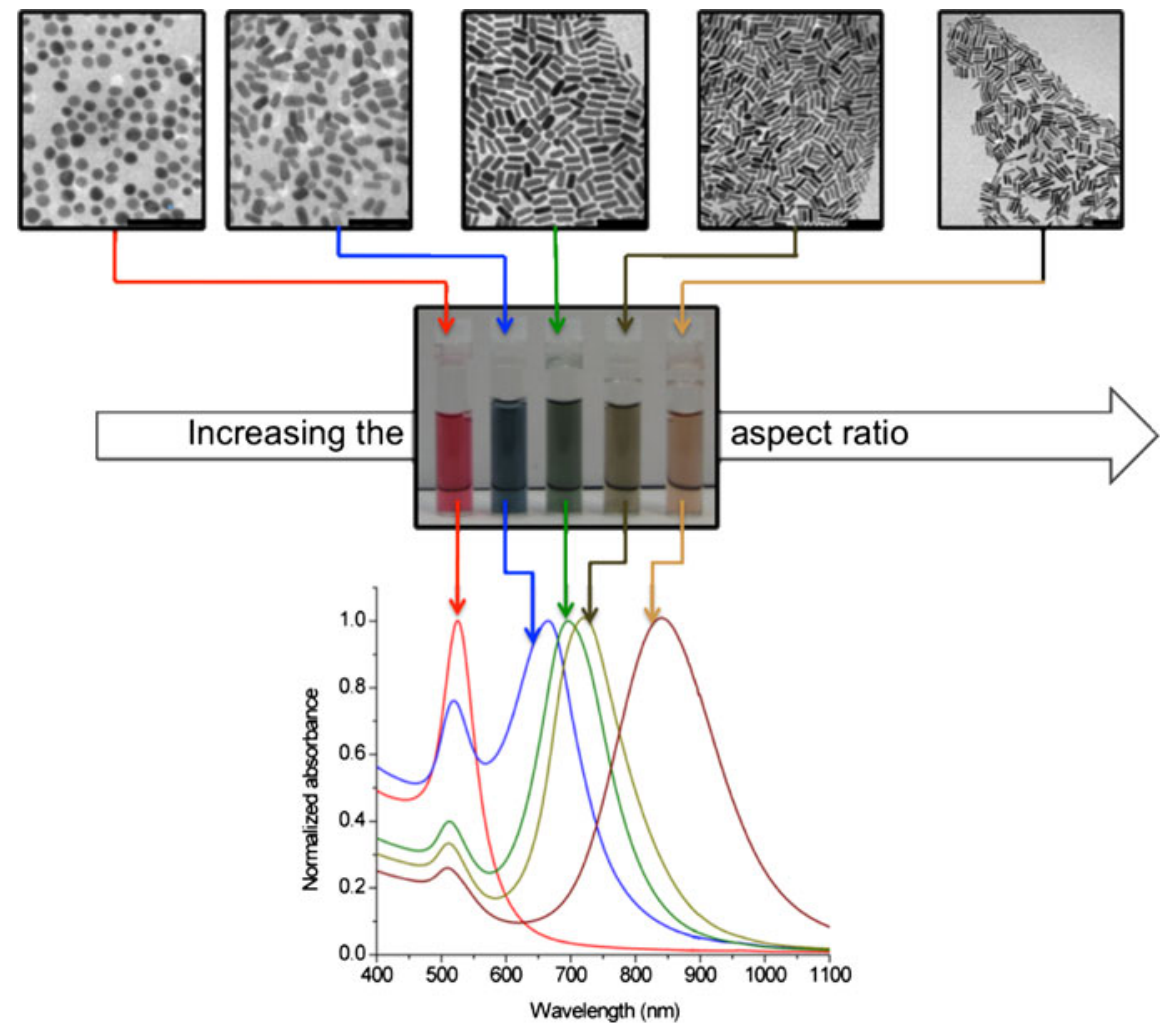

accordingly results in change of the plasmon band position (for a review on the chemical sensing using gold nanoparticles see Murphy et al. 2008a).

The plasmon by its nature creates an electrical field around the excited gold nanoparticles that enhances the Raman scattering cross section of nearby molecules. This phenomenon is the basis of surface-enhanced Raman spectroscopy (SERS) and can lead in, theory, to single molecule detection and identification (Anker et al. 2008). For example, gold spheres, $60 \mathrm{~nm}$ in diameter, functionalized with targeting antibodies, were used as SERS substrates for targeted detection of tumors in living mice (Qian et al. 2008). Anker et al. (2008) have developed an implantable SERS sensor (based on silver structures) to monitor glucose level in a living rat.

The excited electrons in the conduction band lose their energy in form of heat to the surrounding media; the heat generation is the basis of the photothermal therapy (Jain et al. 2008). In these experiments, gold nanoparticles are designed to absorb light in the water window of $\sim 800-1200 \mathrm{~nm}$ by virtue of their shape. Illumination at their absorbance maximum increases the temperature of the solution-some reports state
$>30{ }^{\circ} \mathrm{C}$ (Hirsch et al. 2003). This temperature rise is enough to kill nearby cells (e.g., cancer cells or pathogenic bacteria) (Hirsch et al. 2003; Dickerson et al. 2008; Jain et al. 2008; Norman et al. 2008; von Maltzahn et al. 2009). The optical properties of gold nanoparticles and their corresponding applications are summarized in Fig. 2.

The promise of gold nanoparticles for so many different biological applications has led to a strong interest in studying their potential to cause deleterious effects in biological systems, and how these effects might be mitigated. For the remainder of the Perspective, we focus on recent methods and results that explore the effect of gold nanoparticle exposure on living systems.

Nanoparticle-physiological media interactions

Ultimately, some applications of gold nanoparticles will require that the particles be introduced into a living system (at either the cellular level or at the organismal level). The bloodstream of an organism, the cytoplasm of the cell, and even the media in which cells grow are all complex aqueous mixtures of 
Fig. 2 Schematic showing the physical events that occur as a result of satisfying the localized surface plasmon resonance condition, with the corresponding applications. See text for details

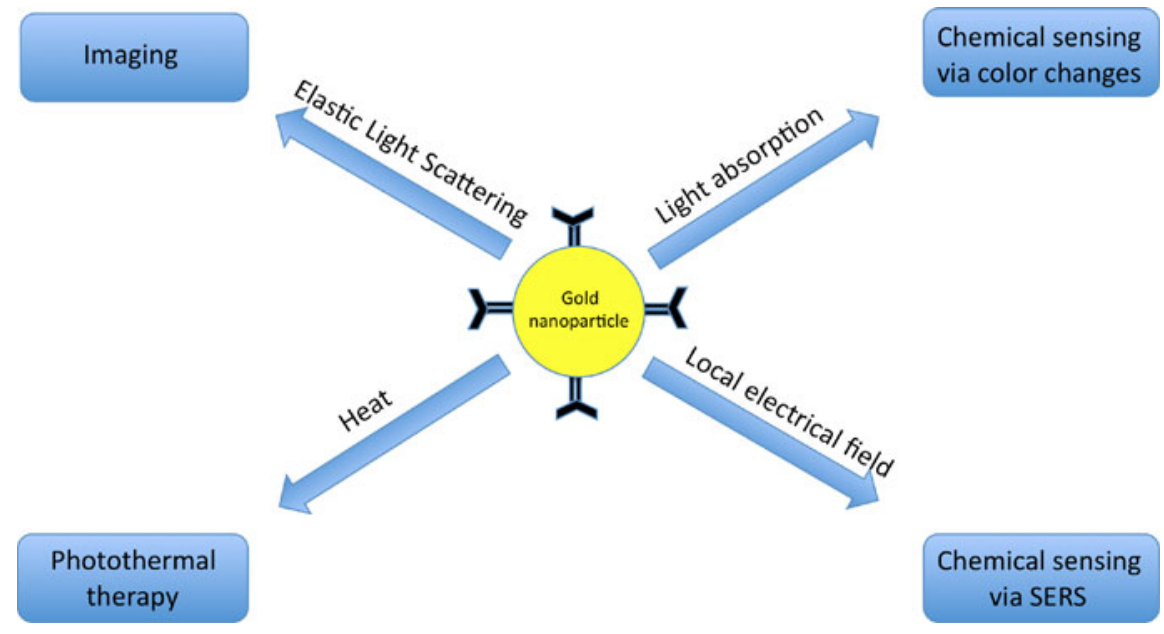

electrolytes, proteins, nutrients, metabolites, etc. What happens at the molecular level when nanoparticles are introduced into these systems? We expect that biological media-nanoparticle interactions precede the next biological steps (distribution, metabolism, elimination, etc.). Thus, understanding the chemical and physical interaction of nanoparticles with the biological media is essential to understanding and predicting the subsequent processes.

The cellular growth media (for in vitro studies) contains serum proteins, essential amino acids, vitamins, electrolytes, and other chemicals (antibiotics, trace metals, etc.). These various components could interact with nanoparticles and change their physiochemical properties such as size and aggregation state, surface charge, and surface chemistry. The nanoparticles, especially if made in aqueous solution, have a surface charge to stabilize them against aggregation via electrostatic repulsion. The presence of electrolytes and the high ionic strength of the biological media can result in nanoparticle aggregation via electrostatic screening (Vesaratchanon et al. 2007). Aggregation of nanoparticles could influence their ability to interact with or enter cells, and thus adds complexity to the system. If the in situ aggregation state of the nanoparticles is not considered, difficulties arise in the interpretation of data about nanoparticle biodistribution or uptake.

Cedervall et al. (2007) demonstrated that many different plasma proteins adsorb on nanoparticles spontaneously, and that the surface chemistry of the nanoparticles in growth media/plasma is not the same as the originally synthesized materials. Instead, the nanoparticles adopt the physiochemical properties of the adsorbed protein shell: a "protein corona" as demonstrated in Fig. 3 (Cedervall et al. 2007; Lynch et al. 2007; Lynch and Dawson 2008).

In the context of studying the nanoparticlegrowth media interaction, in our own work we found that proteins from the growth media adsorb within $5 \mathrm{~min}$ to the surfaces of both cationic and anionic gold nanorods, and increase their hydrodynamic radius. More interestingly, protein adsorption to the surface of the nanorods flips their charge immediately to similar negative value of the serum proteins in the original media (Fig. 3) (Alkilany et al. 2009). Therefore, nanoparticles that had a positive effective surface charge upon preparation are no longer cationic in the cellular media. This is important when considering the molecular effect of charge on toxicity and cellular uptake, and argues against the simple picture, still propagated in the literature, that cationic nanoparticles disrupt the negatively charged cellular membrane by electrostatic interactions.

Protein adsorption to the nanoparticle surface can mediate the uptake of the nanomaterial via receptormediated endocytosis (Conner and Schmid 2003). Therefore, different media with different protein compositions could result in different toxicity and uptake results. This is important when comparing results from different reports addressing the toxicity and uptake of nanoparticles using different methodologies.

In a similar scenario, we expect that the nanoparticle properties will change when injected into blood 
Fig. 3 (Upper panel): Cartoon demonstrating the formation of protein corona on a gold nanoparticle surface. Adsorption of serum proteins onto the surface of gold nanoparticles flips their effective surface charge. (Lower panel): Effective surface charge (zeta potential) of gold nanorods capped with cetyltrimethylammonium bromide, CTAB (white bars) and poly(acrylic acid), PAA (black bars). In aqueous solution, CTABcapped gold nanorods have a positive effective surface charge and PAA-coated nanorods are negative. However, both have the same negative effective surface charge after they mixed with serum proteins and subsequently purified

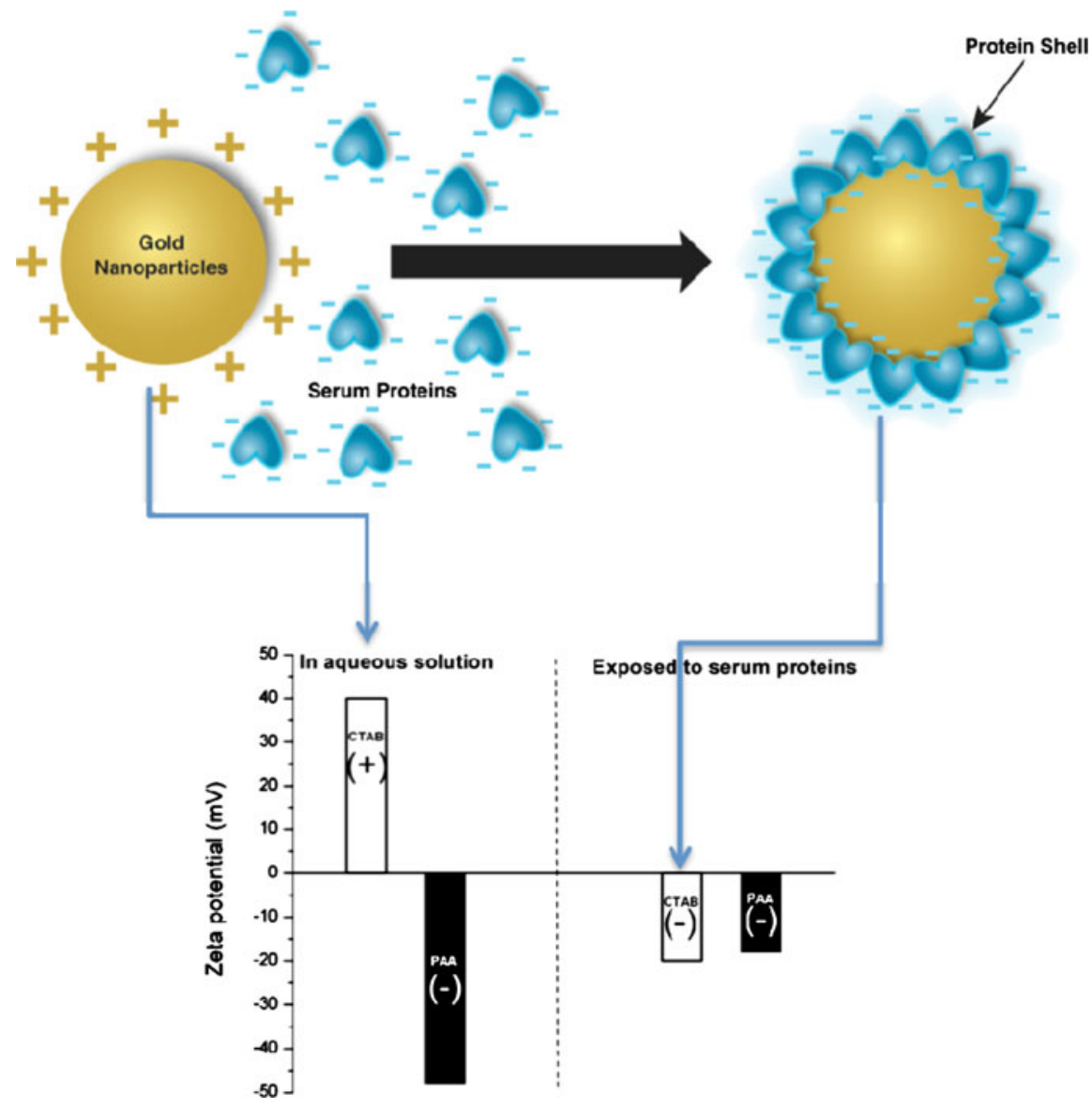

for in vivo animal studies. Blood contains proteins and electrolytes that can change the effective surface charge of the nanoparticles and their aggregation state. For example, it was shown that positively charged gold nanorods aggregated upon mixing with mouse blood for $4 \mathrm{~h}$. However, functionalizing these rods with poly(ethylene) glycol (PEG), a surface treatment commonly used to prevent nonspecific protein adsorption, was found to prevent this aggregation (Eghtedari et al. 2009). The fate of the nanoparticles in blood and their physical and chemical properties in biological fluids should be considered in any in vivo investigation (Dobrovolskaia et al. 2008).

Cellular toxicity of a gold nanoparticle solution: standard methods for in vitro assessment

Over the last decade, many methods to prepare gold nanoparticles of controlled size and shape have been developed (Murphy et al. 2005a; Grzelczak et al. 2008; Jain et al. 2008; Skrabalak et al. 2008), and gold nanorods, in particular, are now commercially available in a range of sizes and shapes from several different chemical companies. In contrast to $\sim 20$ years ago, it is far more common today for chemists who make materials to also assess material biocompatibility. The most common form that biocompatibility studies take is the assessment of toxicity of gold nanoparticles in vitro, meaning in cell culture, using assays similar to those used in drug development screening. Viability assays assess the overall dose-dependent toxicity of nanoparticles on cultured cells, looking for cell survival and proliferation after nanoparticle exposure. We cannot emphasize enough that knowledge of the dose is critical: many drugs that are beneficial at low doses are toxic at high doses. In the literature, however, the dosages of nanoparticles used vary widely across different research groups, and the number of cells exposed to 
their nanoparticles at a given concentration is not always reported.

There are many assays used to measure the cellular impact of a drug that can also be applied to measure the impact of nanoparticle exposure on cells. One common assay is the LDH assay, which is a colorimetric assay measuring the release of lactate dehydrogenase (LDH) into the culture media as an indicator of cellular membrane disruption (Marquis et al. 2009). A metabolic assay considered the "gold standard" for cytotoxicity is the MTT assay, which is a colorimetric assay that measures the enzymatic activity of cellular mitochondria. If cells properly metabolize the MTT dye, the cell culture will turn blue, allowing for simple absorbance measurements to be used to quantify cellular activity (Marquis et al. 2009).

Beyond these relatively simple measures of cell health, many standard assays for other indicators are generally available as commercial kits. These include ROS assays (monitoring oxidative stress by measuring the level of ROS, reactive oxygen species), and real-time polymerase chain reaction amplification and DNA micro-array analysis to examine the expression levels of genes that are, for example, related to stress in the cell. For a recent review addressing the analytical methods to measure nanoparticle toxicity includ uptake, see Marquis et al. 2009. An important point to make about these assays is that many of them rely on colorimetric or fluorescence changes. Since gold nanoparticles absorb light in the visible region, their interference with these assays should be considered (AshaRani et al. 2009). In addition, as noted in the previous section, gold nanoparticles can adsorb molecules (such as indicator dyes) from the surrounding media (Alkilany et al. 2008) and thus quench their fluorescence (Willets and Van Duyne 2007); thus nanomaterial interference with fluorescence-based assays should also be considered and controlled.

To measure cellular response is one task; to measure how many nanoparticles are actually taken up by cells, and where they are localized within the cell, and what happens to the nanoparticles over time, is quite another. To qualitatively measure cellular uptake, gold nanoparticles can be visualized in microtomed-cell slices after exposure by transmission electron microscopy (TEM), which takes advantage of the high electron density of gold nanoparticles. Dark field optical microscopy can be performed on living cells to visualize the location of gold nanoparticles (within the diffraction limits of the instrument, typically $\sim 200 \mathrm{~nm}$ ) which takes advantage of the elastic light scattering properties of the gold nanoparticles from the plasmon bands (Stone et al. 2007). Fluorescence microscopy can be used with living cells, if fluorescent dyes are conjugated to the nanoparticles (but special care should be taken to minimize quenching by the gold core). These techniques, however, are semiquantitative at best. Quantification of gold nanoparticle uptake by cells is best performed by a technique that has high specificity and low limits of detection such as inductively coupled plasma mass spectrometry (ICP-MS). ICPMS has excellent limits of detection (18 parts per trillion for gold) and can be applied to quantify the cellular uptake by digesting the cells with strong acid (Alkilany et al. 2009). While ICP-MS is an excellent quantitative tool, it is a destructive technique, and cannot differentiate between nanoparticles adsorbed to the surface of the cell and internalized into cells. Treatment of cells with heparin sulfate before analyzing the cells can be used to desorb surfaceadsorbed nanoparticles, assuming that heparin sulfate polymer has a higher binding affinity to the cellular surface to displace surface-bound gold nanoparticles (Liu et al. 2007). Another approach is to selectively etch the gold nanoparticles on the surface of the cells, as was demonstrated by Cho et al. (2009a) using solutions of $\mathrm{I}_{2}$ and KI. ICP-MS analysis combined with $\mathrm{I}_{2} / \mathrm{KI}$ etching was used to quantify the number of gold nanoparticles both "on" and "in" the cells (Cho et al. 2009a).

Cellular toxicity of a gold nanoparticle solution: nanoparticle solution versus supernatant

Pharmaceutical drugs have different functional groups within their chemical structure that determine their solubility, stability, pharmacological activity, and pharmacokinetics properties. Similarly, nanoparticles are multi-component systems that may have surface capping agents, antifouling molecules, recognition molecules, etc. The simplest gold nanoparticle solution contains the core material (gold) and surface-bound stabilizing ligands, and, potential leftover chemicals from the synthesis. Observed toxicity from a gold nanoparticle solution could arise from any of these components, and thus evaluating the 
contribution of each component is essential to understand the origin of toxicity (Alkilany et al. 2009). For example, preparing gold nanorods using a standard seed-mediated approach requires the use of a cationic surfactant (cetyltrimethylammonium bromide, CTAB) (Sau and Murphy 2004; Murphy et al. 2005b). This preparation is the main one that has been commercialized, and users of these materials need to be conscious of the reagents involved. CTAB molecules form a bilayer on the surface of the gold nanorods and direct the nanorod growth in one direction (Nikoobakht and El-Sayed 2001). Indeed, the use of the CTAB molecules is essential and thus the gold nanorods are "born" with bound surfactant, giving the nanorods a high positive charge (Nikoobakht and El-Sayed 2001; Murphy et al. 2005b). CTAB alone is a quite toxic to cells at submicromolar dose (Alkilany et al. 2009). Free CTAB molecules in gold nanoparticle solutions can originate from inadequate purification or desorption of surfactant from the surface of the nanorods. We quantitatively confirmed that free CTAB molecules in gold nanorod solutions are responsible for their apparent toxicity, and not the rods themselves, by comparing the toxicity of the "whole" gold nanorod solution and its supernatant after centrifugation to remove the nanorods. The toxicity of the supernatant (which contains no nanorods) found to be similar to the whole gold nanorod solution even at maximum purification (Fig. 4). Furthermore, the CTAB level in the supernatant, as measured by liquid chromatography/mass spectrometry, was found to be similar to the required dose to reduce the viability to the observed values (Alkilany et al. 2009). These results strongly highlight the importance of comparing the supernatant toxicity with the original nanoparticle solution as a valuable control experiment to understand the origin of the nanoparticles toxicity: are the nanoparticles themselves toxic, or are the surrounding chemicals responsible for apparent toxicity?

Knowledge of the origin of nanoparticle toxicity allows chemists to design solutions to mitigate the toxicity. In the case of CTAB-capped nanoparticles, various approaches have been employed to retard CTAB desorption and to eliminate the free CTAB molecules in nanoparticle solutions. For example, overcoating CTAB-capped gold nanorods with a polyelectrolyte reduces their toxicity significantly by retarding the physical desorption of the CTAB molecules (Hauck et al. 2008; Leonov et al. 2008; Alkilany et al. 2009). Another approach is to fix a polymerizable version of the CTAB surfactant via
Fig. 4 "The supernatant control". A gold nanorod solution is exposed to cells, and in this cartoon kills $70 \%$ of the cells at a certain dose. An identical gold nanorod solution is centrifuged, and the colorless supernatant exposed to cells. The similar toxicity of both solutions indicates that the nanoparticles are not toxic by themselves, but small molecules (leftover reagents, or desorbed capping agents) are

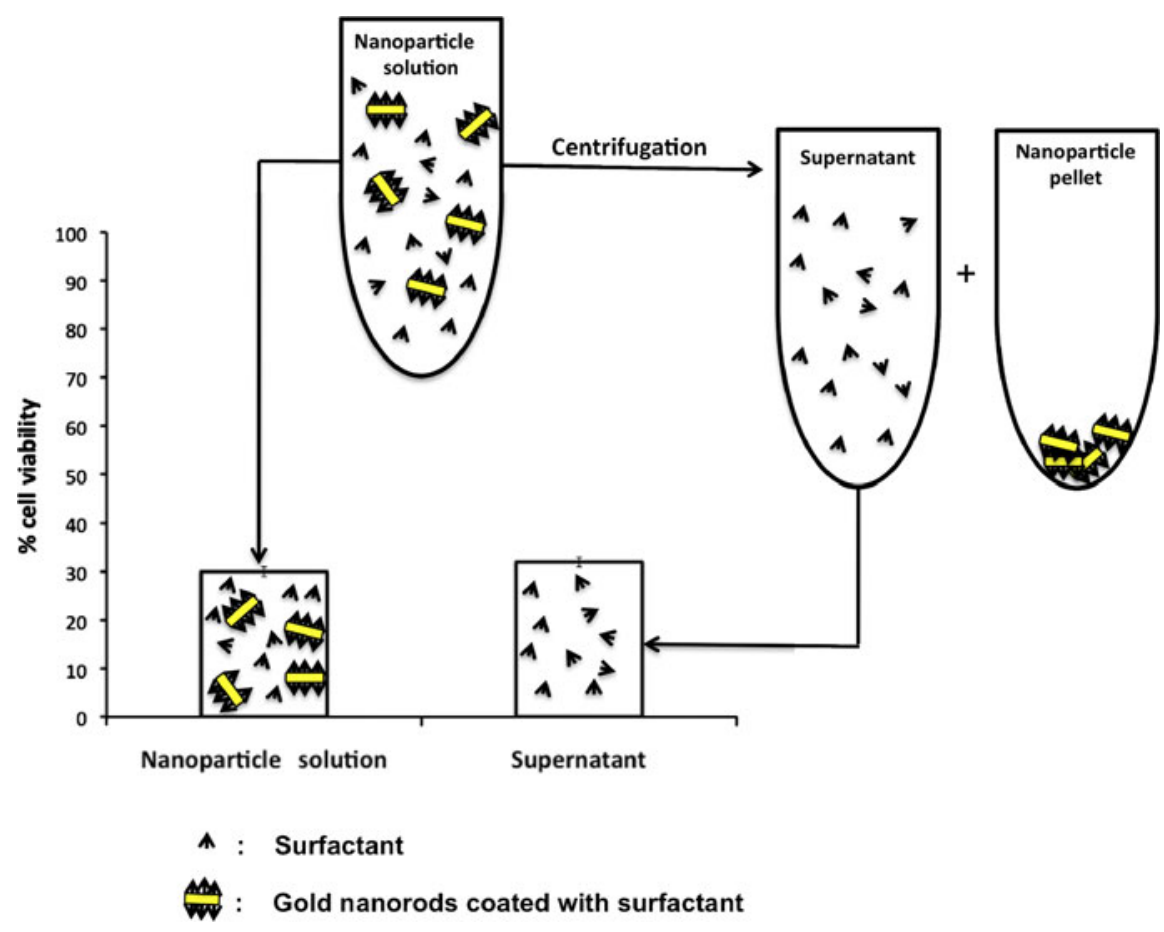


free radical polymerization on the nanoparticles surface; this was shown to hinder the desorption of the surfactant molecules (Alkilany and Murphy 2009). An additional approach would be to develop methods to make the original gold nanorods with a more biocompatible molecule; however, so far progress on this front has been limited, and requires a more thorough understanding of how the nanorods crystallize and grow. Yet another approach to enhance the biocompatibility of nanomaterials is to replace/exchange the surface-bound CTAB molecules with more biocompatible molecules such as PEG or phospholipids (Takahashi et al. 2006). Takahashi et al. extracted the CTAB from aqueous solution of gold nanorods using a chloroform phase that contained phosphatidylcholine (Takahashi et al. 2006). This surface ligand replacement did not induce particle aggregation but did enhance the biocompatibility of the gold nanorods compared to the CTABcapped nanoparticles (Takahashi et al. 2006). The above examples demonstrate the ability to manipulate the toxicity of gold nanoparticles if the origin of the toxicity is identified (in our case the surfactant desorption).

Standard biological assays for nanoparticle toxicity and biodistribution

\section{In vivo assessment}

A whole organism is much more complex than a single cell; therefore more toxicological studies are required to assess the safety of nanoparticles at the whole animal level, in vivo. These studies should include general health indicators such as behavioral abnormality, weight loss, percent of mortality, and average life span. Specific tissue-level toxicological studies include the hepatotoxicity (liver), nephrotoxicity (kidney), immunogenicity, hematological toxicity (blood), and inflammatory and oxidative responses due to the nanoparticles. The specific parameters of these studies have been summarized elsewhere (Dobrovolskaia and McNeil 2007; Aillon et al. 2009).

Drug pharmacokinetics is the sum of vital processes including drug absorption, distribution, metabolism, and elimination. Before any drug obtains regulatory approval, its pharmacokinetic parameters should be determined. Similar to pharmaceutical drugs, studying the pharmacokinetics of nanoparticles in vivo to assess their absorption, biodistribution, metabolism, elimination processes is essential (Chen et al. 2009). The biodistribution of gold nanoparticles into different tissues can be studied by isolation of the targeted organ, followed by acid digestion to oxidize and extract the gold ions, which can be then quantified by ICP-MS. The same concept can be employed to study the blood and renal clearance of gold nanoparticles by analyzing the gold content in the blood or urine samples as a function of time. After obtaining the required information about the level of gold nanoparticles in different compartments (blood and urine) as function of time, classical pharmacokinetics models can be applied to obtain important pharmacokinetic parameters such as volume of distribution $\left(V_{\mathrm{d}}\right)$, maximum plasma concentration $\left(C_{\max }\right)$, blood half time $\left(t_{1 / 2}\right)$, total body clearance (Cl), etc. (Cho et al. 2009b).

Given this brief overview of the issues and methods, we now turn to the results of specific studies in which gold nanoparticles were introduced into either in vitro or in vivo systems.

Recent results of gold nanoparticles effects on cells in vitro

\section{In vitro cytotoxicity}

Nanoparticles could have many adverse effects at the cellular level by interacting with vital cell components such as the membrane, mitochondria, or nucleus. Adverse outcomes could include organelle or DNA damage, oxidative stress, apoptosis (programmed cell death), mutagenesis, and protein up/ down regulation (Unfried et al. 2007; Aillon et al. 2009; Jia et al. 2009; Pan et al. 2009). Since it is simpler to perform, most nanotoxicological screening studies are done in vitro, on cell cultures in plates. Even though these results may not accurately predict the in vivo toxicity (Griffith and Swartz 2006), it does provide a basis for understanding the mechanism of toxicity and nanoparticle uptake at the cellular level.

Gold nanoparticles have been found to be "nontoxic" according to many reports. Using a human leukemia cell line, gold nanospheres of different sizes (4, 12, and $18 \mathrm{~nm}$ in diameter) and capping agents (citrate, cysteine, glucose, biotin, and cetyltrimethylammonium bromide) were found to be nontoxic 
based on the MTT assay (Connor et al. 2005). Similar results were obtained using gold nanoparticles (spheres, $3.5 \mathrm{~nm}$ in diameter) on immune system cell lines (Shukla et al. 2005). In this study, gold nanoparticles entered the cell by (presumably) endocytosis, did not induce any toxicity, and reduced the level of reactive oxygen species. Villiers et al. studied the toxicity of citrate-capped gold nanoparticles (spheres, $10 \mathrm{~nm}$ in diameter) on dendritic cells (part of the human immune system, which process and present antigens on their surfaces for other cells). They found that nanoparticles were not cytotoxic, did not induce activation, and did not change phenotype of the cells (Villiers et al. 2009).

In contrast to these results, other groups have found that gold nanoparticles are "toxic". For example, Goodman et al. found that cationic gold nanospheres ( $2 \mathrm{~nm}$ in diameter) are toxic (at certain doses). Interestingly, the same nanoparticles with a negatively charged surface found to be not toxic at the same concentration and in the same cell line (Goodman et al. 2004). This observation was explained by the ability of the cationic nanoparticles to interact with the negatively charged cellular membrane and the resultant membrane disruption (Goodman et al. 2004). However, neither nanoparticle interaction with the culture media, nor the supernatant toxicity of the nanoparticle solution was studied. Pan et al. (2009) found that 1.4-nm gold nanospheres triggered necrosis, mitochondrial damage, and induced an oxidative stress on all examined cell line (Table 1). Interestingly, they found no evidence for cellular damage for 15 -nm gold nanospheres bearing the same surface group (Pan et al. 2009). This result highlights possible size-dependent toxicity of gold nanoparticles (Pan et al. 2009). In particular, gold nanoparticles less than $2 \mathrm{~nm}$ in diameter show evidence of chemical reactivity that does not occur at larger sizes (Turner et al. 2008).

The conflicting results could arise from the variability of the used toxicity assays, cell lines, and nanoparticles chemical/physical properties. For example, cytotoxicity results can vary with the used cell line. Citrate-capped gold nanoparticles $(13 \mathrm{~nm}$ in diameter) were found to be toxic to a human carcinoma lung cell line but not to human liver carcinoma cell line at same dosage (Patra et al. 2007). Furthermore, the dosing parameters and the exposure time of gold nanoparticles to the cells in these studies vary, making it difficult to compare. Recent results of gold nanoparticle toxicity to cells in vitro are summarized in Table 1.

In vitro three-dimensional (3D) cell culture models have been used as a bridge between the in vitro twodimensional (2D) plated cell culture and the in vivo models (Griffith and Swartz 2006; Yamada and Cukierman 2007). In this context, Lee et al. compared the toxicity of gold nanoparticles in both $2 \mathrm{D}$ and $3 \mathrm{D}$ cell culture constructs. They used hydrogel inverted colloidal crystals as a cell growth substrate and human hepatocarcinoma cells to construct the 3D cell culture environment. They found that toxicity of both citrate (anionic)- and CTAB (cationic) capped gold nanoparticles were significantly reduced in the $3 \mathrm{D}$ environment compared to 2D (Lee et al. 2009). These results point out that in vitro studies alone are not adequate to assess toxicity of nanoparticles.

\section{In vitro cellular uptake}

As discussed in the previous sections, there are various methods to visualize and measure gold nanoparticle concentration inside cells. Since gold nanoparticles are electron-dense, it is easy to distinguish them from other cellular components using TEM. Other techniques that could be used for imaging nanoparticle location are dark field optical microscopy, fluorescence microscopy, and differential interference contrast microcopy (Marquis et al. 2009). To quantify the number of nanoparticles per cell, ICP-MS is an excellent technique to analyze gold content inside the cells or the remaining portion in the growth media (Marquis et al. 2009).

Understanding the mechanism of gold nanoparticle uptake by cells is important for intracellular drug and gene delivery (Rosi et al. 2006; Han et al. 2007). To internalize macromolecules and particles, cells utilize phagocytosis, micropinocytosis, and receptormediated endocytosis (RME) pathways including caveolae-mediated, clathrin-mediated, and caveolae/ clathrin independent endocytosis (Conner and Schmid 2003). These pathways operate using different receptors, cellular signaling cascades, and type of particles (Dobrovolskaia and McNeil 2007). For example, phagocytosis operates for particles $>500 \mathrm{~nm}$, where smaller particles enter via the RME pathways (Dobrovolskaia and McNeil 2007; Hess and Tseng 2007). 


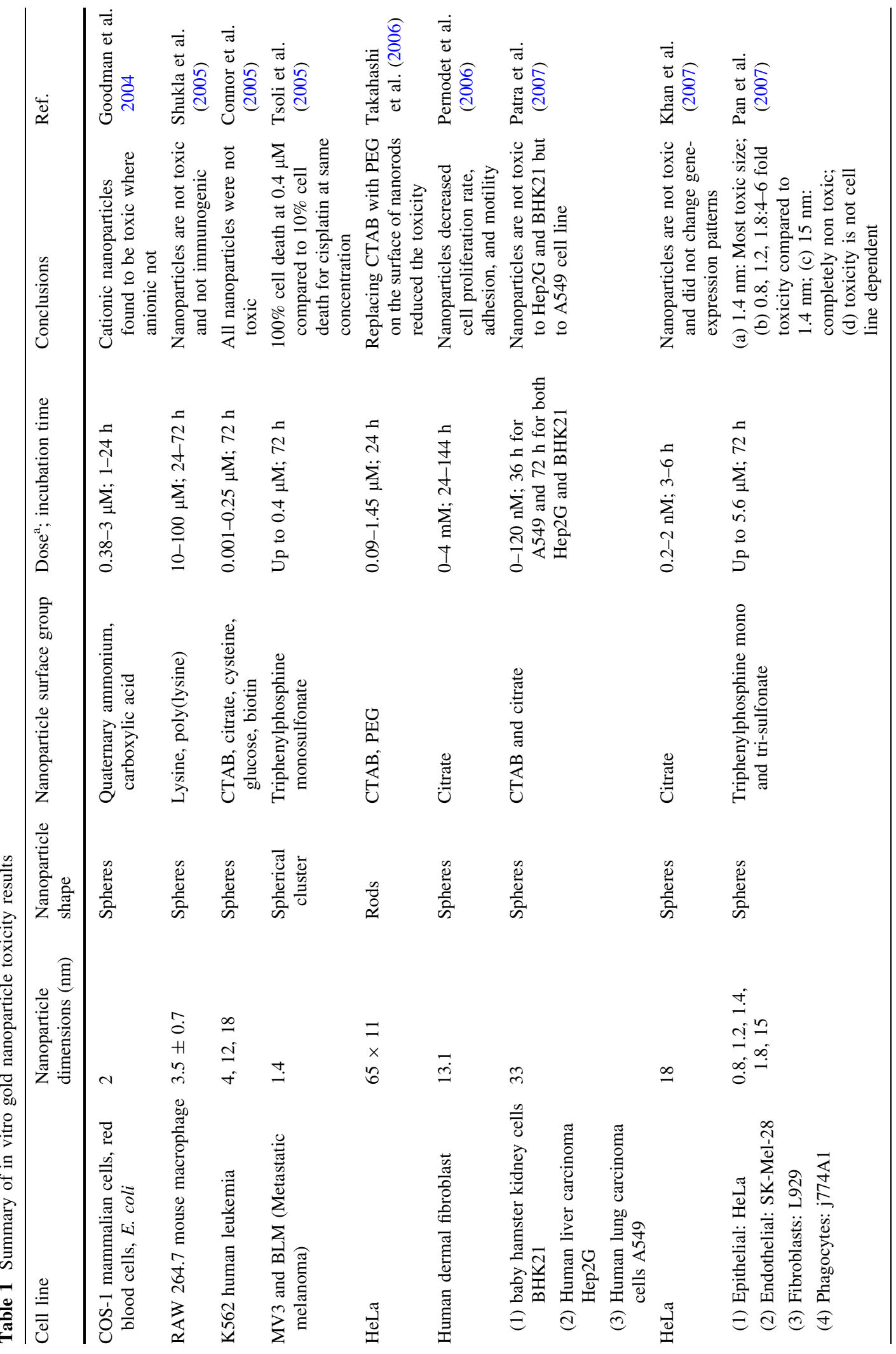




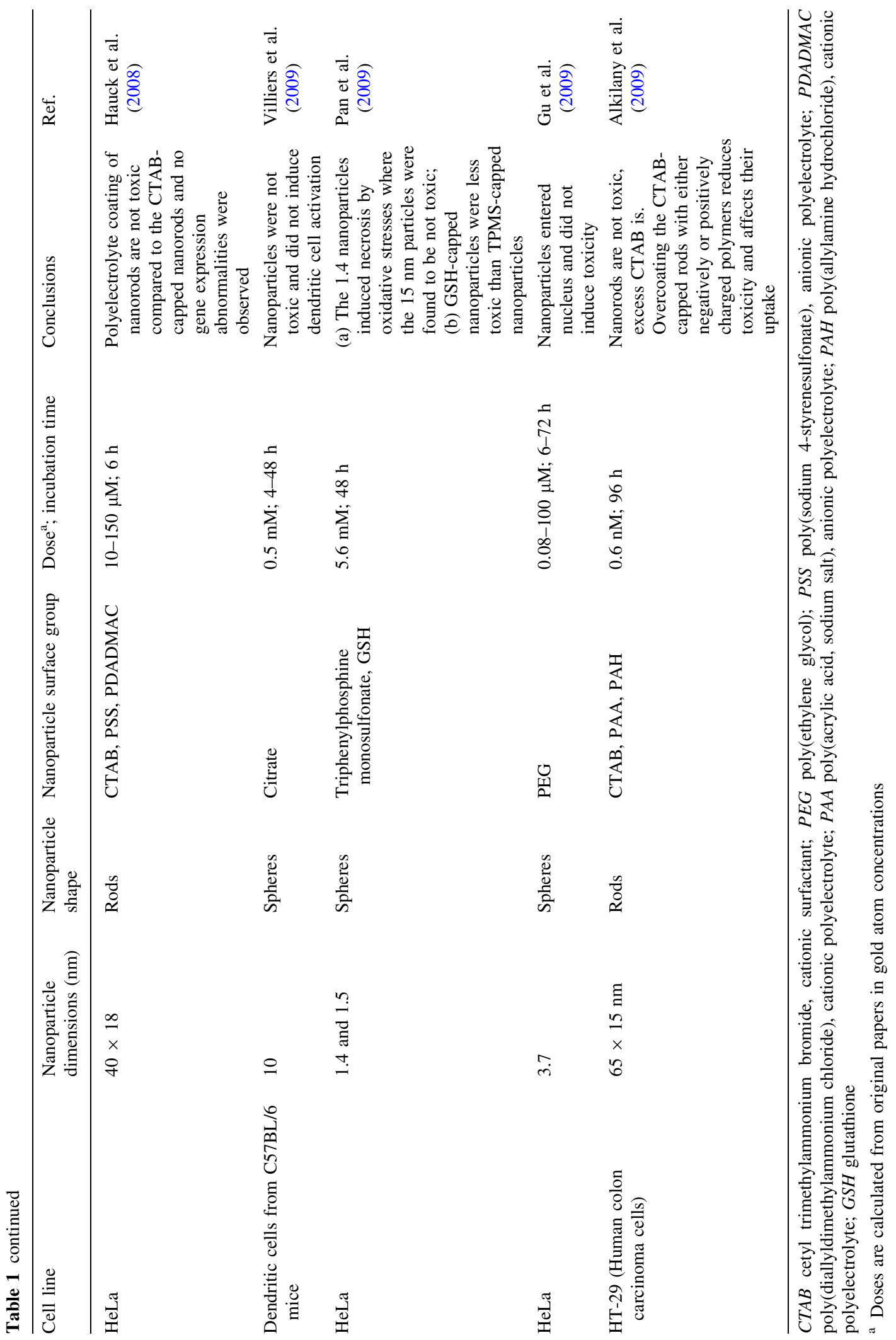


For gold nanoparticles, most of the studied nanoparticles have dimensions less than $100 \mathrm{~nm}$ and RME has been proposed as the primary mechanism of cellular entry (Shukla et al. 2005; Chithrani and Chan 2007; Nativo et al. 2008). Chithrani et al. studied the mechanism by which transferrin-coated gold nanorods and nanospheres were taken up by three types of cultured cell lines: STO, HeLa, and SNB19 which are fibroblast, ovarian cancer, and brain tumor cells, respectively. Transferrin is a plasma protein for iron transportation, which enters cells via a RME mechanism. They found a $70 \%$ decrease in nanoparticle cellular uptake at $4{ }^{\circ} \mathrm{C}$ compared to $37^{\circ} \mathrm{C}$, a standard experiment that supports the use of the RME pathway by the nanoparticles. Drastic decreases in nanoparticle cellular uptake were observed when either hypertonic environments (by adding sucrose) or $\mathrm{K}^{+}$ depleted media were used, which indicates clatherinmediated endocytosis as the specific mechanism of uptake (Chithrani and Chan 2007).

The size of nanoparticles was found to play a critical role in both the rate and extent of cellular uptake. It was found that $50 \mathrm{~nm}$ transferrin-coated gold nanoparticles were taken up by mammalian cells at higher rates and extents compared to smaller and larger sizes in the range of $10-100 \mathrm{~nm}$ (Chithrani et al. 2006). The explanation of this optimal size was based on the so-called "wrapping effect", which describes how a cellular membrane encloses nanoparticles. Two factors dictate how fast and how many nanoparticles enter the cellular compartment via "wrapping": the first is the free energy that results from ligand-receptor interaction; the second is the receptor diffusion kinetics onto the wrapping sites on the cellular membrane. Considering the contribution of these factors and using mathematical calculations, Gao et al. (2005) suggested that nanoparticles with 27-30 nm diameter would have that fastest wrapping time and thus the fastest receptor-mediated endocytosis.

Even though ligand-mediated uptake of gold nanoparticles is considered to be a general mechanism for their cellular entry, gold nanoparticles with "special" surface chemistries/arrangements can enter cells by direct penetration. Verma et al. (2008) showed that gold nanospheres $(\sim 5 \mathrm{~nm})$ decorated with two capping molecules (anionic and hydrophobic, with alternating positions on the surface) enter the cells directly (endocytosis-independent entry) without destruction to the cell membrane in an action similar to the cell-penetrating peptides.

Intracellular distribution of gold nanoparticles has been studied, with the general conclusion that gold nanoparticles are able to enter cells and are trapped in vesicles, but are not able to enter the nucleus (Shukla et al. 2005; Pernodet et al. 2006; Chithrani and Chan 2007; Khan et al. 2007; Alkilany et al. 2009). Using TEM, Nativo et al. showed that $16 \mathrm{~nm}$ citrate-capped gold nanoparticles enter cells readily (incubation time $2 \mathrm{~h}$ ) and are trapped into endosomes. They did not find free nanoparticles in the cytosol or the nucleus. However, they were able to deliver the nanoparticles to the cytosol and nucleus by modifying these nanoparticles with cell-penetrating and nuclear-localizing peptides (Nativo et al. 2008).

However, other reports indicate nuclear penetration for gold nanoparticles without special surface functionalization. For example, gold nanoparticles with diameters of $1.4 \mathrm{~nm}$ were able to enter the nucleus in metastatic melanoma cells and bind DNA with high efficiency $(24.5 \%$ of the total internalized gold nanoparticles bound to DNA) (Tsoli et al. 2005). In another study using citrate-capped gold nanospheres ( $5 \mathrm{~nm}$ in diameter), $25 \%$ of the internalized gold nanoparticles were able to enter the nucleus in HeLa cells without any surface functionalization. This fraction was doubled when the nanoparticles were functionalized with a nuclear-penetrating peptide (Ryan et al. 2007).

The general conclusions that can be drawn from studies are still preliminary. Different investigators use different cell lines, different sizes of nanoparticles, different surface groups, different doses, different time points, and may or may not have quantitative information (as opposed to qualitative visualization) about nanoparticle uptake into cells. Table 2 summarizes the quantitative results of gold nanoparticle uptake by cultured cells, calculated as the number of nanoparticles per cell.

In vivo studies: biodistribution and toxicity of gold nanoparticles in organisms

There is a real need to investigate the in vivo results exposure to nanomaterials before any potential therapeutic applications (Fischer and Chan 2007). In this context, Chen et al. studied the toxicity of wide size range of citrate-capped gold nanoparticles (spheres of 
Table 2 Summary of in vitro gold nanoparticle uptake results

\begin{tabular}{|c|c|c|c|c|c|c|c|}
\hline Cell line & $\begin{array}{l}\text { Nanoparticle } \\
\text { dimensions }(\mathrm{nm})\end{array}$ & $\begin{array}{l}\text { Nanoparticle } \\
\text { shape }\end{array}$ & $\begin{array}{l}\text { Nanoparticle } \\
\text { surface group }\end{array}$ & $\begin{array}{l}\text { Dose }^{\mathrm{a}} \\
\text { incubation } \\
\text { time }\end{array}$ & $\begin{array}{l}\text { Cellular uptake } \\
\text { (gold nanoparticles/cell) }\end{array}$ & $\begin{array}{l}\text { Analytical } \\
\text { method }\end{array}$ & Ref. \\
\hline HeLa & $\begin{array}{l}40 \times 18 \\
\quad(\text { length } \times \text { width })\end{array}$ & Rods & $\begin{array}{l}\text { CTAB, PAH, } \\
\text { PSS, } \\
\text { PDADMAC }\end{array}$ & $\begin{array}{l}1.0 \mathrm{nM} \\
6 \mathrm{~h}\end{array}$ & $\begin{array}{l}150,000 \text { for PDAMAC; } \\
12,000 \text { for PAH; } 12,000 \\
\text { for CTAB; } 1,000 \text { for PSS }\end{array}$ & ICP-AES & $\begin{array}{l}\text { Hauck et al. } \\
\text { (2008) }\end{array}$ \\
\hline HT-29 & $\begin{array}{l}65 \times 15 \\
\quad(\text { length } \times \text { width })\end{array}$ & Rods & $\begin{array}{l}\text { CTAB, PAA, } \\
\text { PAH }\end{array}$ & $\begin{array}{l}0.2 \mathrm{nM} \\
96 \mathrm{H}\end{array}$ & $\begin{array}{l}45 \pm 6 \text { for CTAB; } \\
270 \pm 20 \text { for PAA; } \\
2,320 \pm 140 \text { for } \mathrm{PAH}\end{array}$ & ICP-MS & $\begin{array}{l}\text { Alkilany } \\
\text { et al. } \\
\text { (2009) }\end{array}$ \\
\hline SK-BR-3 & 17.7 & Spheres & $\begin{array}{l}\text { Citrate, PAH, } \\
\text { PVA }\end{array}$ & $\begin{array}{l}0.027 \mathrm{nM} \\
24 \mathrm{~h}\end{array}$ & $\begin{array}{l}\text { 1,800 for citrate; } 5,200 \text { for } \\
\text { PAH; } 900 \text { for PVA }\end{array}$ & ICP-MS & $\begin{array}{l}\text { Cho et al. } \\
\text { (2009a, } \\
\text { 2009b) }\end{array}$ \\
\hline SK-BR-3 & $\begin{array}{l}50 \times 20 \\
\quad(\text { length } \times \text { width })\end{array}$ & Rods & $\begin{array}{l}\text { CTAB, PEG, } \\
\text { anti-HER } 2\end{array}$ & $\begin{array}{l}0.06 \mathrm{nM} \\
24 \mathrm{~h}\end{array}$ & $\begin{array}{l}\text { 8,000 for CTAB; } 3,000 \text { for } \\
\text { PEG; 4,400 for anti-HER } 2\end{array}$ & ICP-MS & $\begin{array}{l}\text { Cho et al. } \\
\text { (2010) }\end{array}$ \\
\hline U87MG & $\begin{array}{l}50 \times 5 \mathrm{~nm}(\text { edge } \\
\text { length } \times \text { wall } \\
\text { thickness })\end{array}$ & Cages & $\begin{array}{l}\text { Anti-EGFR, } \\
\text { PEG }\end{array}$ & $\begin{array}{l}0.02 \mathrm{nM} \\
24 \mathrm{~h}\end{array}$ & $\begin{array}{r}826 \pm 50 \text { for anti-EGFR } \\
\text { and } 190 \pm 31 \text { for PEG }\end{array}$ & ICP-MS & $\begin{array}{c}\text { Au et al. } \\
(2010)\end{array}$ \\
\hline
\end{tabular}

CTAB Cetyl trimethylammonium bromide, cationic surfactant; PDADMAC poly(diallyldimethylammonium chloride), cationic polyelectrolyte; $P A H$ poly(allylamine hydrochloride), cationic polyelectrolyte; $P A A$ poly(acrylic acid, sodium salt), anionic polyelectrolyte; PSS poly(sodium 4-styrenesulfonate), anionic polyelectrolyte; $P V A$ poly(vinyl alcohol) slightly anionic polymer; $P E G$ poly(ethylene glycol), neutral polymer; Anti-HER 2 monoclonal antibodies that recognize human epidermal growth factor 2 $\left(\mathrm{HER}_{2}\right)$ receptors, anti-EGFR monoclonal antibodies that recognize epidermal growth factor (EGER) receptors, ICP-AES inductively-coupled plasma atomic emission spectroscopy, ICP-MS inductively-coupled plasma mass spectrometry

${ }^{\text {a }}$ Doses and cellular uptake values are calculated from the original papers in gold nanoparticle (not atoms) concentration

diameter: $3,5,8,12,17,37,50,100 \mathrm{~nm}$ ) in mice. They found that the smallest sizes ( 3 and $5 \mathrm{~nm}$ ) and the largest size (50 and $100 \mathrm{~nm}$ ) are not toxic at the dose they were using (Table 3). However, they found that the intermediate size range of $8-37 \mathrm{~nm}$ had lethal effects on mice inducing severe sickness, loss of appetite, weight loss, change in fur color, and shorter average lifespan (Chen et al. 2009). The systematic toxicity of the intermediate size range $(18-37 \mathrm{~nm})$ was linked to major organ damage in the liver, spleen, and lungs (Chen et al. 2009). Interestingly, in the same study, the same "lethal" nanoparticles were not toxic in vitro using HeLa cell lines (Fig. 5) (Chen et al. 2009). This study demonstrated a large discrepancy between the in vitro and in vivo results, and highlights the notion that simple in vitro experiments may not lead to good predictions regarding in vivo results.

The mechanism of in vivo nanoparticle toxicity could arise from many sources. For example, injecting gold nanoparticles in the blood could cause either blood clotting or hemolysis (blood cells break open and release their hemoglobin) (Dobrovolskaia et al. 2008). Encouragingly, citrate-capped gold nanoparticles (spheres of diameter 30 and $50 \mathrm{~nm}$ ) have been shown to be "blood compatible" and did not induce any detectable platelet aggregation, change in plasma coagulation time, or immune response in at least one study (Dobrovolskaia et al. 2009).

Because the size range of nanoparticles matches that of proteins or even small viruses, one might expect that the immune system might react strongly to the presence of nanoparticles in the body resulting in induced immunotoxicity (Dobrovolskaia and McNeil 2007). Even though antigen-bound gold nanoparticles were used as vaccine carriers to augment immune responses toward antigens (Bastus et al. 2009), little is known about their intrinsic in vivo antigenicity and inflammatory properties.

Accumulation of nanomaterials in the liver and spleen after being taken up by the reticuloendothelial system (part of the immune system with complex components communicate to identify, capture, and filter foreign antigens and particulates) could lead to hepatic and splenic toxicity (Chen et al. 2009). Cho et al. (2009b) studied the toxicity of $13 \mathrm{~nm}$ PEGmodified gold nanoparticles in mice and found that the nanoparticles accumulate in the liver after 


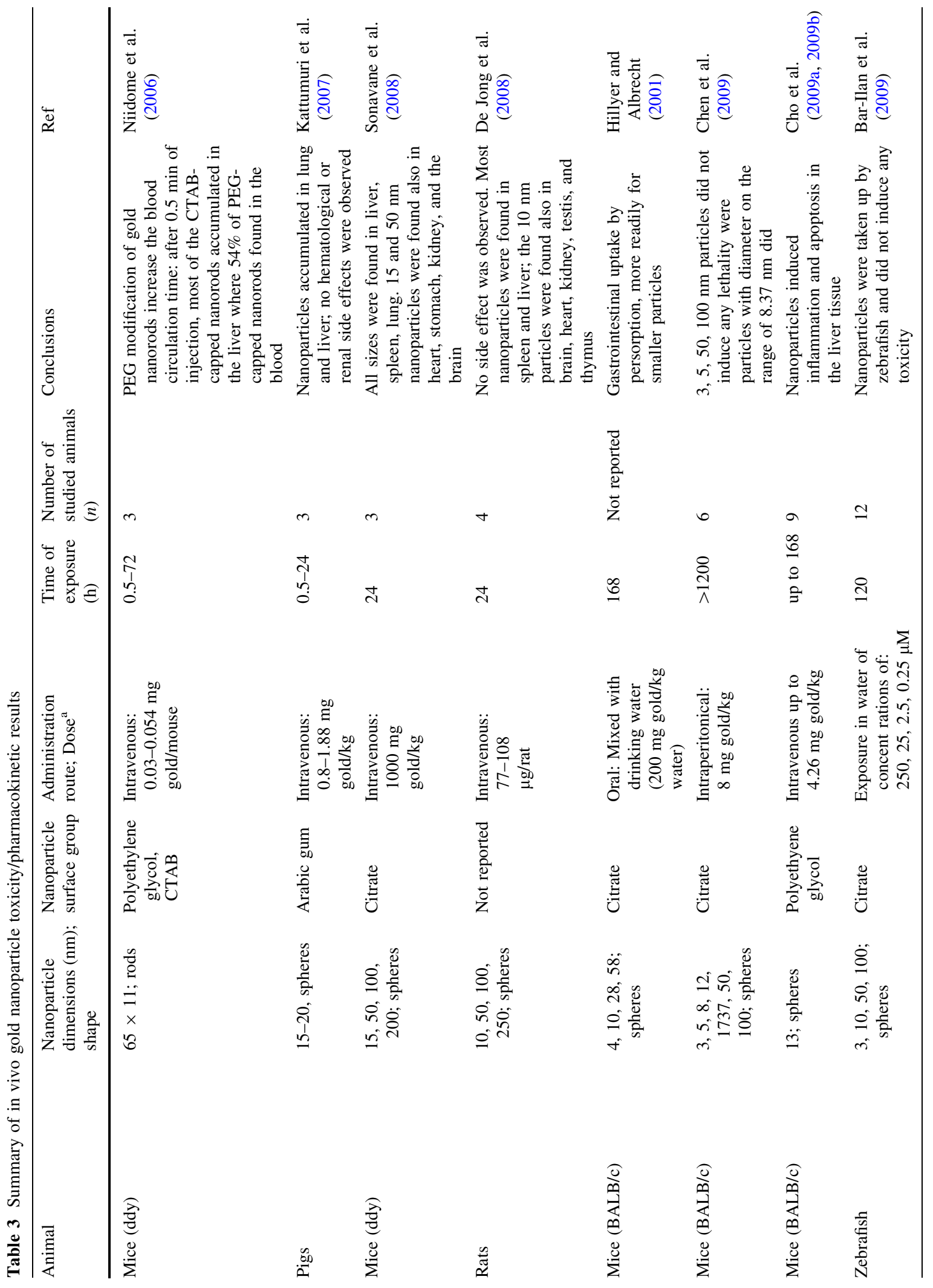




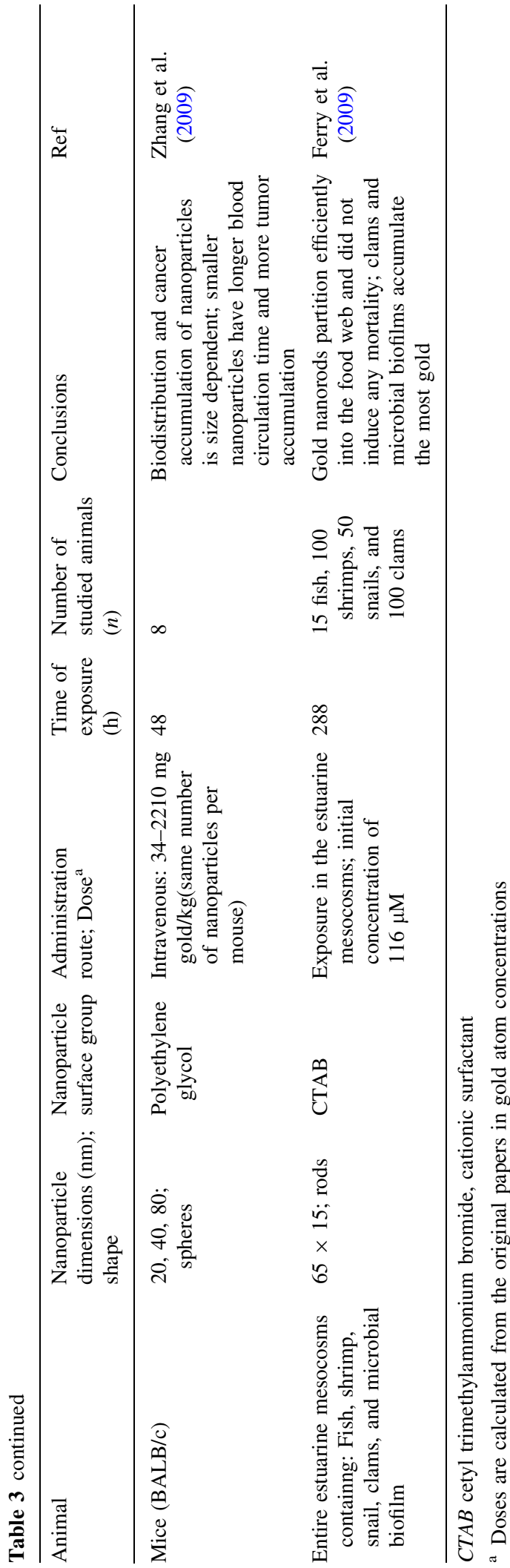

injection, and induce acute inflammation and cellular damage in the mouse liver.

The physical and chemical properties of nanoparticles can affect their pharmacokinetics such as absorption, metabolism, distribution, and elimination. For example, Hillyer and Albrecht (2001) showed that the absorption of gold nanoparticles following oral administration to mice is size-dependent. Smaller nanoparticles were found to cross the gastrointestinal wall more readily after oral intake. Other studies investigated the bio-distribution of gold colloid after intravenous injection in rats. De Jong et al. injected rats with 10, 50, 100, $250 \mathrm{~nm}$ gold nanoparticles and after $24 \mathrm{~h}$ rats were killed and gold concentration in different organs were quantified by ICP-MS. Their data showed that the smallest size $(10 \mathrm{~nm})$ nanoparticles were found in the blood, spleen, liver, testis, lung, and brain; the larger sizes were found only in spleen and kidney (De Jong et al. 2008). In a very similar study, Sonavane et al. (2008) showed that $15 \mathrm{~nm}$ is the most widely distributed size in vivo among a nanoparticle library with diameters from 15 to $200 \mathrm{~nm}$, and that 15 and $50 \mathrm{~nm}$ nanoparticles were able to enter the brain. These findings highlight the size-dependent biodistribution of gold nanoparticles in vivo.

According to FDA guidelines, pharmaceutical drugs should be eliminated via metabolism or excretion processes after they enter the body. Drug elimination reduces toxicity and prevents drug accumulation. Similar to pharmaceutical drugs, nanoparticles should be designed to be eliminated in the body. Indeed, nanoparticle elimination should be considered seriously, since they are more resistant to elimination routes such as metabolism and renal excretion. No long-term studies on gold nanoparticles have been reported to our knowledge. As one related example, injected semiconductor quantum dots in mice remained intact for more than 2 years in mouse tissues, retaining their fluorescence activity (Ballou et al. 2007). This resistance might be because of their large size (too large to be filtered from the kidney) and their higher chemical stability (against dissolution and degradation) compared to molecules. It is thought that nanoparticles should have final hydrodynamic diameters $\leq 5.5 \mathrm{~nm}$ to be excreted from the rat body by the renal route (Choi et al. 2007). Since the majority of the studied gold nanoparticles are larger than this renal filtration cutoff, in the few studies that have been performed, the gold 




Fig. 5 Left: average lifespan of mice receiving gold nanoparticles, $8-37 \mathrm{~nm}$ in diameter, was shortened compared to smaller and larger nanoparticle sizes. The break marks on the top of bars indicate that no death was observed during the

nanoparticles were not excreted in urine; instead they were found to be eliminated from the blood by the reticuloendothelial system (RES) and thus to accumulate in the spleen and liver (De Jong et al. 2008; von Maltzahn et al. 2009).

Little effort has been made to match the properties of a nanoparticle with the size that might be acceptable for elimination from an organism. In the case of gold, anisotropic rod-shaped nanoparticles are desired to absorb in the near-infrared region, preferably with small dimensions to be excreted from the body (say nanorods with dimension of $4 \mathrm{~nm}$ in length and $1 \mathrm{~nm}$ in width, aspect ratio 4). Preparing nanorods with these dimensions is very difficult, and is not available at present; and gold particles less than $4 \mathrm{~nm}$ in one dimension would be sufficiently small to become chemically reactive. In a rare effort to synthesize a gold nanoparticle that can absorb light in the NIR region of the spectra and be eliminated from the body, Troutman et al. (2008) prepared goldcoated liposomes. The idea is that the gold nanoparticles would serve as a shell to provide the plasmonic properties, and the liposome would serve as a carrier (Fig. 6). Upon disintegration of these plasmon-resonant liposomes by physiological stimuli such as phospholipase A2 (which degrade the liposome's lipid), the composite dissolves and the nanoparticles are suspended freely, with an average diameter of $5.7 \mathrm{~nm}$ (Troutman et al. 2008). However, the elimination of these nanoparticle-liposome composites

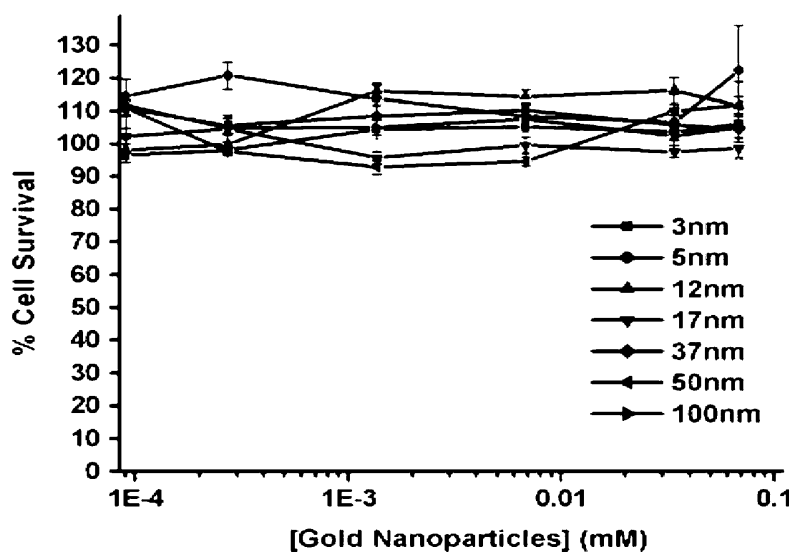

experimental period. Right: MTT assay for the same gold nanoparticles using the HeLa cell line. Images reproduced with permission from (Chen et al. 2009). Copyright: Springer Science

has not been investigated yet. The degree of metabolism and degradability of a nanomaterial is very important to prevent bioaccumulation and facilitate elimination. However, very little known about this issue in the literature and more research should be performed in this direction.

While most of the in vivo studies have been performed using land animal models (mice, rats, and pigs), Bar-Ilan et al. (2009) used zebrafish embryo screening methods to assess the toxicity of both gold and silver nanoparticles of different sizes (3, 10, 50, and $100 \mathrm{~nm}$ ). Zebrafish is an excellent in vivo model which has been used to assess environmental toxicity due its high degree of homology to the human genome and its very similar physiological responses to xeno-substances as mammals (Parng 2005; Fako

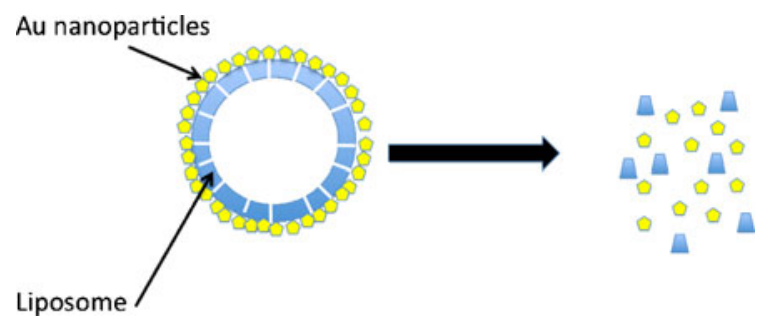

Fig. 6 Cartoon demonstrates the concept of the biodegradable plasmon-resonant liposomes. The whole composite absorbs in the near-infrared region and thus serve as "nanoheaters" to destroy cancer cells. Upon disruption of the carrier (liposomes), the nanoparticles could be released and have a higher chance to be bio-eliminated 
and Furgeson 2009). Interestingly, they found that gold nanoparticles were not toxic to zebrafish but the silver nanoparticles with comparable size were highly toxic (inducing $100 \%$ death after $120 \mathrm{~h}$ post-fertilization) (Bar-Ilan et al. 2009).

Even as knowledge advances to the point that nanoparticles can be properly manufactured for a specific goal in an organism (e.g. detection or treatment for a disease), the entire life cycle of the nanoparticle needs to be considered. It is well-known, for example, that certain toxins can bio-accumulate in organisms, and thus enter the food chain. How would nanoparticles move through a food web, from organism to organism? In this context, Ferry et al. studied the fate of CTAB-coated gold nanorods $(65 \mathrm{~nm}$ length $\times 15 \mathrm{~nm}$ width) in replicate estuarine mesocosms consisting of seawater, sediment, microbial biofilms, snails, fish, clams, and shrimps to model the complexity of a tidal marsh creek. They found that nanoparticles partitioned into most of the organisms (none of which died at the dosage used, which was designed to mimic a viral load in the ecosystem) to very different extents, with a low concentration remaining in water (Ferry et al. 2009). The largest accumulations of nanoparticles by far were the microbial biofilms and clams (filter feeders). The results of recent gold nanoparticle animal studies in vivo are summarized in Table 3.

\section{Conclusion and perspective}

The available literature reports, both in vitro and in vivo, vary widely in their methods and conclusions (Ostrowski et al. 2009). Many reports indicate that gold nanoparticles are nontoxic; however, others contradict this finding. To draw a complete conclusion, more studies are needed which:

- Include critical nanoparticle characterization both prior to and after mixing with the biological media, with a focus on the change of the physical properties such as aggregation state, effective surface charge, degree and identity of protein adsorption, and desorption of chemicals from the surface of the nanoparticles.

- Include careful control experiments such as the discussed "supernatant control" experiment in Fig. 4 (Alkilany et al. 2009; Bar-Ilan et al. 2009)
- While many studies focus on determining the lethal dosage of nanoparticles $\left(\mathrm{LD}_{50}\right.$, dose required to kill half of the population), little if any focus on determination of the effective therapeutic dosage of these nanoparticles $\left(\mathrm{ED}_{50}\right.$, dose required to produce therapeutic response in $50 \%$ of the population). Determining the $\mathrm{ED}_{50}$ experimentally will help nanotoxicologists to use more realistic dosing to assess the toxicity of nanoparticles.

- Most the studies where conducted on simple gold nanoparticles (citrate or CTAB capped). Efforts are needed to study the toxicity and pharmacokinetics of functionalized gold nanoparticles with real surface composition (e.g. recognition and non-fouling molecules) since this surface modification can significantly alter the whole story.

- The major administration route in the reported in vivo studies is intravenous injection. More investigation is needed to study the toxicity of gold nanoparticles using different route of exposure such as inhalation, oral absorption, and dermal absorption of gold nanoparticles.

Hope for the future

Even though the collective results in the literature show controversy about the toxicity of gold nanoparticles, we think that the uptake and toxicity of these nanomaterials are controllable and can be manipulated. As discussed earlier in this perspective, researchers have demonstrated the ability to "detoxify" and regulate the uptake of these nanoparticles by functionalizing the surface of the nanoparticles with smart/benign ligands. In an encouraging recent example, one single intravenous injection of PEGfunctionalized gold nanorods which showed a long circulating time $\left(t_{1 / 2} 17 \mathrm{~h}\right)$ was able to destroy human xenogaft tumors in mice (von Maltzahn et al. 2009). In this study, the total dose of nanorods required for complete photothermal destruction of the tumor was $20 \mathrm{mg} / \mathrm{kg}$ (in gold atoms) and did not induce any toxicity in tumor-free mice (von Maltzahn et al. 2009). As more data are collected, we are optimistic that proper attention will be paid to surface chemistry and dosages, so that the full potential of gold nanoparticles for biomedical applications can be exploited. 


\section{References}

Aillon KL, Xie YM, El-Gendy N, Berkland CJ, Forrest ML (2009) Effects of nanomaterial physicochemical properties on in vivo toxicity. Adv Drug Deliv Rev 61:457-466. doi:10.1016/j.addr.2009.03.010

Alivisatos AP (1996) Semiconductor clusters, nanocrystals, and quantum dots. Science 271:933-937

Alkilany AM, Murphy CJ (2009) Gold nanoparticles with a polymerizable surfactant bilayer: synthesis, polymerization, and stability evaluation. Langmuir 25:13874-13879. doi:10.1021/la901270x

Alkilany AM, Frey RL, Ferry JL, Murphy CJ (2008) Gold nanorods as nanoadmicelles: 1-naphthol partitioning into a nanorod-bound surfactant bilayer. Langmuir 24:1023510239. doi:10.1021/la8018343

Alkilany AM, Nagaria PK, Hexel CR, Shaw TJ, Murphy CJ, Wyatt MD (2009) Cellular uptake and cytotoxicity of gold nanorods: molecular origin of cytotoxicity and surface effects. Small 5:701-708. doi:10.1002/smll.200801546

Anker JN, Hall WP, Lyandres O, Shah NC, Zhao J, Van Duyne RP (2008) Biosensing with plasmonic nanosensors. Nat Mater 7:442-453. doi:10.1038/nmat2162

AshaRani PV, Mun GLK, Hande MP, Valiyaveettil S (2009) Cytotoxicity and genotoxicity of silver nanoparticles in human cells. ACS Nano 3:279-290. doi:10.1021/nn8005 96wER

Au L, Zhang Q, Cobley CM et al (2010) Quantifying the cellular uptake of antibody-conjugated Au nanocages by two-photon microscopy and inductively coupled plasma mass spectrometry. ACS Nano 4:35-42. doi:10.1021/ nn901392mER

Ballou B, Ernst LA, Andreko S et al (2007) Sentinel lymph node imaging using quantum dots in mouse tumor models. Bioconjug Chem 18:389-396. doi:10.1021/bc060261j

Bar-Ilan O, Albrecht RM, Fako VE, Furgeson DY (2009) Toxicity assessments of multisized gold and silver nanoparticles in zebrafish embryos. Small 5:1897-1910. doi: 10.1002/smll.200801716

Bastus NG, Sanchez-Tillo E, Pujals S et al (2009) Peptides conjugated to gold nanoparticles induce macrophage activation. Mol Immunol 46:743-748. doi:10.1016/ j.molimm.2008.08.277

Cedervall T, Lynch I, Foy M et al (2007) Detailed identification of plasma proteins adsorbed on copolymer nanoparticles. Angew Chem Int Ed 46:5754-5756. doi:10.1002/ anie. 200700465

Chen YS, Hung YC, Liau I, Huang GS (2009) Assessment of the in vivo toxicity of gold nanoparticles. Nanoscale Res Lett 4:858-864. doi:10.1007/s11671-009-9334-6

Chithrani BD, Chan WCW (2007) Elucidating the mechanism of cellular uptake and removal of protein-coated gold nanoparticles of different sizes and shapes. Nano Lett 7:1542-1550. doi:10.1021/n1070363y

Chithrani BD, Ghazani AA, Chan WCW (2006) Determining the size and shape dependence of gold nanoparticle uptake into mammalian cells. Nano Lett 6:662-668. doi: $10.1021 / \mathrm{n} 10523960$

Cho EC, Xie JW, Wurm PA, Xia YN (2009a) Understanding the role of surface charges in cellular adsorption versus internalization by selectively removing gold nanoparticles on the cell surface with a $\mathrm{I}_{2} / \mathrm{KI}$ etchant. Nano Lett 9:1080 1084. doi: $10.1021 / \mathrm{n} 1803487 \mathrm{r}$

Cho WS, Cho MJ, Jeong J et al (2009b) Acute toxicity and pharmacokinetics of $13 \mathrm{~nm}$-sized PEG-coated gold nanoparticles. Toxicol Appl Pharmacol 236:16-24. doi: 10.1016/j.taap.2008.12.023

Cho EC, Liu Y, Xia Y (2010) A simple spectroscopic method for differentiating cellular uptakes of gold nanospheres and nanorods from their mixtures. Angew Chem Int Ed 49:1976-1980. doi:10.1002/anie.200906584

Choi HS, Liu W, Misra P et al (2007) Renal clearance of quantum dots. Nat Biotechnol 25:1165-1170. doi: $10.1038 /$ nbtl 340

Colvin VL (2003) The potential environmental impact of engineered nanomaterials. Nat Biotechnol 21:1166-1170. doi:10.1038/nbt875

Conner SD, Schmid SL (2003) Regulated portals of entry into the cell. Nature 422:37-44. doi:10.1038/nature01 451ER

Connor EE, Mwamuka J, Gole A, Murphy CJ, Wyatt MD (2005) Gold nanoparticles are taken up by human cells but do not cause acute cytotoxicity. Small 1:325-327. doi: 10.1002/smll.200400093

De Jong WH, Hagens WI, Krystek P, Burger MC, Sips AJAM, Geertsma RE (2008) Particle size-dependent organ distribution of gold nanoparticles after intravenous administration. Biomaterials 29:1912-1919. doi:10.1016/ j.biomaterials.2007.12.037

Dickerson EB, Dreaden EC, Huang XH et al (2008) Gold nanorod assisted near-infrared plasmonic photothermal therapy (PPTT) of squamous cell carcinoma in mice. Cancer Lett 269:57-66. doi:10.1016/j.canlet.2008.04.026

Dobrovolskaia MA, McNeil SE (2007) Immunological properties of engineered nanomaterials. Nat Nanotechnol 2:469-478. doi:10.1038/nnano.2007.223

Dobrovolskaia MA, Aggarwal P, Hall JB, McNeil SE (2008) Preclinical studies to understand nanoparticle interaction with the immune system and its potential effects on nanoparticle biodistribution. Mol Pharm 5:487-495. doi: 10.1021/mp800032f

Dobrovolskaia MA, Patri AK, Zheng JW et al (2009) Interaction of colloidal gold nanoparticles with human blood: effects on particle size and analysis of plasma protein binding profiles. Nanomedicine 5:106-117. doi:10.1016/ j.nano.2008.08.001

Eghtedari M, Oraevsky A, Copland JA, Kotov NA, Conjusteau A, Motamedi M (2007) High sensitivity of in vivo detection of gold nanorods using a laser optoacoustic imaging system. Nano Lett 7:1914-1918. doi:10.1021/ n1070557d

Eghtedari M, Liopo AV, Copland JA, Oraevslty AA, Motamedi M (2009) Engineering of hetero-functional gold nanorods for the in vivo molecular targeting of breast cancer cells. Nano Lett 9:287-291. doi:10.1021/n180 $2915 q$

Fako VE, Furgeson DY (2009) Zebrafish as a correlative and predictive model for assessing biomaterial nanotoxicity. Adv Drug Deliv Rev 61:478-486. doi:10.1016/j.addr. 2009.03.008 
Ferrari M (2005) Cancer nanotechnology: opportunities and challenges. Nat Rev Cancer 5:161-171. doi:10.1038/ nrc1566

Ferry JL, Craig P, Hexel C et al (2009) Transfer of gold nanoparticles from the water column to the estuarine food web. Nat Nanotechnol 4:441-444. doi:10.1038/NNANO. 2009.157ER

Finkelstein AE, Walz DT, Batista V, Mizraji M, Roisman F, Misher A (1976) Auranofin: new oral gold compound for treatment of rheumatoid-arthritis. Ann Rheum Dis 35:251-257. doi:10.1136/ard.35.3.251

Fischer HC, Chan WCW (2007) Nanotoxicity: the growing need for in vivo study. Curr Opin Biotechnol 18:565-571. doi:10.1016/j.copbio.2007.11.008

Gao HJ, Shi WD, Freund LB (2005) Mechanics of receptormediated endocytosis. Proc Natl Acad Sci USA 102:9469-9474. doi:10.1073/pnas.0503879102

Goodman CM, McCusker CD, Yilmaz T, Rotello VM (2004) Toxicity of gold nanoparticles functionalized with cationic and anionic side chains. Bioconjug Chem 15:897900. doi:10.1021/bc049951i

Griffith LG, Swartz MA (2006) Capturing complex 3D tissue physiology in vitro. Nat Rev Mol Cell Biol 7:211-224. doi: $10.1038 / \mathrm{nrm} 1858$

Grzelczak M, Perez-Juste J, Mulvaney P, Liz-Marzan LM (2008) Shape control in gold nanoparticle synthesis. Chem Soc Rev 37:1783-1791. doi:10.1039/b711490g

Gu YJ, Cheng JP, Lin CC, Lam YW, Cheng SH, Wong WT (2009) Nuclear penetration of surface functionalized gold nanoparticles. Toxicol Appl Pharmacol 237:196-204. doi: 10.1016/j.taap.2009.03.009

Han G, Ghosh P, Rotello VM (2007) Functionalized gold nanoparticles for drug delivery. Nanomedicine 2:113123. doi: $10.2217 / 17435889.2 .1 .113$

Hauck TS, Ghazani AA, Chan WCW (2008) Assessing the effect of surface chemistry on gold nanorod uptake, toxicity, and gene expression in mammalian cells. Small 4:153-159. doi:10.1002/smll.200700217

Helmus M (2007) The need for rules and regulations. Nat Nanotechnol 2:333-334. doi:10.1038/nnano.2007.165

Hess H, Tseng Y (2007) Active intracellular transport of nanopartides: opportunity or threat? ACS Nano 1:390392. doi: $10.1021 / \mathrm{nn} 700407 \mathrm{v}$

Hillyer JF, Albrecht RM (2001) Gastrointestinal persorption and tissue distribution of differently sized colloidal gold nanoparticles. J Pharm Sci 90:1927-1936. doi:10.1002/ jps. 1143

Hirsch LR, Stafford RJ, Bankson JA et al (2003) Nanoshellmediated near-infrared thermal therapy of tumors under magnetic resonance guidance. Proc Natl Acad Sci USA 100:13549-13554. doi:10.1073/pnas.2232479100

Jain PK, Huang XH, El-Sayed IH, El-Sayed MA (2008) Noble metals on the nanoscale: optical and photothermal properties and some applications in imaging, sensing, biology, and medicine. Acc Chem Res 41:1578-1586. doi: 10.1021/ar7002804

Jia HY, Liu Y, Zhang XJ et al (2009) Potential oxidative stress of gold nanoparticles by induced-NO releasing in serum. J Am Chem Soc 131:40-41. doi:10.1021/ja808033w

Kattumuri V, Katti K, Bhaskaran S et al (2007) Gum arabic as a phytochemical construct for the stabilization of gold nanoparticles: in vivo pharmacokinetics and X-ray-contrast-imaging studies. Small 3:333-341. doi:10.1002/smll. 200600427

Kelly KL, Coronado E, Zhao LL, Schatz GC (2003) The optical properties of metal nanoparticles: the influence of size, shape, and dielectric environment. J Phys Chem B 107:668-677. doi:10.1021/jp026731y

Khan JA, Pillai B, Das TK, Singh Y, Maiti S (2007) Molecular effects of uptake of gold nanoparticles in HeLa cells. Chembiochem 8:1237-1240. doi:10.1002/cbic.200700165

Lal S, Clare SE, Halas NJ (2008) Nanoshell-enabled photothermal cancer therapy: impending clinical impact. Acc Chem Res 41:1842-1851. doi:10.1021/ar800150g

Lee J, Lilly GD, Doty RC, Podsiadlo P, Kotov NA (2009) In vitro toxicity testing of nanoparticles in 3D cell culture. Small 5:1213-1221. doi:10.1002/smll.200801788

Leonov AP, Zheng JW, Clogston JD, Stern ST, Patri AK, Wei A (2008) Detoxification of gold nanorods by treatment with polystyrenesulfonate. ACS Nano 2:2481-2488. doi: $10.1021 / \mathrm{nn} 800466 \mathrm{c}$

Lewinski N, Colvin V, Drezek R (2008) Cytotoxicity of nanoparticles. Small 4:26-49. doi:10.1002/smll.2007 00595

Liu YL, Shipton MK, Ryan J, Kaufman ED, Franzen S, Feldheim DL (2007) Synthesis, stability, and cellular internalization of gold nanoparticles containing mixed peptide-poly(ethylene glycol) monolayers. Anal Chem 79:2221-2229. doi:10.1021/ac061578f

Lynch I, Dawson KA (2008) Protein-nanoparticle interactions. Nano Today 3:40-47. doi:10.1016/S1748-0132(08) 70014-8

Lynch I, Cedervall T, Lundqvist M, Cabaleiro-Lago C, Linse S, Dawson KA (2007) The nanoparticle-protein complex as a biological entity; a complex fluids and surface science challenge for the 21st century. Adv Colloid Interface Sci 134-135:167-174. doi:10.1016/j.cis.2007.04.021

Marquis BJ, Love SA, Braun KL, Haynes CL (2009) Analytical methods to assess nanoparticle toxicity. Analyst 134:425-439. doi:10.1039/b818082b

Maynard AD, Aitken RJ, Butz T et al (2006) Safe handling of nanotechnology. Nature 444:267-269. doi:10.1038/ $444267 \mathrm{a}$

Metz O, Stoll W, Plenert W (1982) Meningosis prophylaxis with intrathecal Au-198-colloid and methotrexate in childhood acute lymphocytic-leukemia. Cancer 49:224228. doi:10.1002/1097-0142(1982115)49:2<224:AID-CN CR2820490205>3.0.CO;2-O

Murphy CJ, San TK, Gole AM et al (2005a) Anisotropic metal nanoparticles: synthesis, assembly, and optical applications. J Phys Chem B 109:13857-13870. doi:10.1021/ jp0516846

Murphy CJ, Sau TK, Gole A, Orendorff CJ (2005b) Surfactantdirected synthesis and optical properties of one-dimensional plasmonic metallic nanostructures. MRS Bull 30:349-355

Murphy CJ, Gole AM, Hunyadi SE et al (2008a) Chemical sensing and imaging with metallic nanorods. Chem Commun 5:544-557. doi:10.1039/b711069c

Murphy CJ, Gole AM, Stone JW et al (2008b) Gold nanoparticles in biology: beyond toxicity to cellular imaging. Acc Chem Res 41:1721-1730. doi:10.1021/ar800035u 
Nativo P, Prior IA, Brust M (2008) Uptake and intracellular fate of surface-modified gold nanoparticles. ACS Nano 2:1639-1644. doi:10.1021/nn800330a

Nel A, Xia T, Madler L, Li N (2006) Toxic potential of materials at the nanolevel. Science 311:622-627. doi: 10.1126/science. 1114397

Niidome T, Yamagata M, Okamoto Y, Akiyama Y, Takahashi H, Kawano T, Katayama Y, Niidome Y (2006) PEGmodified gold nanorods with a stealth character for in vivo applications. J Control Release 114:343-347. doi: 10.1016/j.jconrel.2006.06.017

Nikoobakht B, El-Sayed MA (2001) Evidence for bilayer assembly of cationic surfactants on the surface of gold nanorods. Langmuir 17:6368-6374. doi:10.1021/la010530o

Norman RS, Stone JW, Gole A, Murphy CJ, Sabo-Attwood TL (2008) Targeted photothermal lysis of the pathogenic bacteria, Pseudomonas aeruginosa, with gold nanorods. Nano Lett 8:302-306. doi:10.1021/n10727056

Oberdorster G, Sharp Z, Atudorei V et al (2004) Translocation of inhaled ultrafine particles to the brain. Inhal Toxicol 16:437-445. doi:10.1080/08958370490439597

Ostrowski AD, Martin T, Conti J, Hurt I, Harthorn BH (2009) Nanotoxicology: characterizing the scientific literature, 2000-2007. J Nanopart Res 11:251-257. doi:10.1007/ s11051-008-9579-5

Pan Y, Neuss S, Leifert A et al (2007) Size-dependent cytotoxicity of gold nanoparticles. Small 3:1941-1949. doi: 10.1002/smll.200700378ER

Pan Y, Leifert A, Ruau D et al (2009) Gold nanoparticles of diameter $1.4 \mathrm{~nm}$ trigger necrosis by oxidative stress and mitochondrial damage. Small 5(18):2067-2076. doi: 10.1002/smll.200900466

Parng C (2005) In vivo zebrafish assays for toxicity testing. Curr Opin Drug Discov Dev 8:100-106

Patra HK, Banerjee S, Chaudhuri U, Lahiri P, Dasgupta AK (2007) Cell selective response to gold nanoparticles. Nanomedicine 3:111-119. doi:10.1016/j.nano.2007.03.005

Pernodet N, Fang XH, Sun Y et al (2006) Adverse effects of citrate/gold nanoparticles on human dermal fibroblasts. Small 2:766-773. doi:10.1002/smll.200500492ER

Qian XM, Peng XH, Ansari DO, Yin-Goen Q, Chen GZ, Shin DM, Yang L, Young AN, Wang MD, Nie SM (2008) In vivo tumor targeting and spectroscopic detection with surface-enhanced Raman nanoparticle tags. Nat Biotechnol 26:83-90. doi:10.1038/nbt1377

Rosi NL, Mirkin CA (2005) Nanostructures in biodiagnostics. Chem Rev 105:1547-1562. doi:10.1021/cr030067f

Rosi NL, Giljohann DA, Thaxton CS, Lytton-Jean AKR, Han MS, Mirkin CA (2006) Oligonucleotide-modified gold nanoparticles for intracellular gene regulation. Science 312:1027-1030. doi:10.1126/science.1125559

Ryan JA, Overton KW, Speight ME et al (2007) Cellular uptake of gold nanoparticles passivated with BSA-SV40 large $\mathrm{T}$ antigen conjugates. Anal Chem 79:9150-9159. doi:10.1021/ac0715524

Sarin H, Kanevsky AS, Wu HT et al (2008) Effective transvascular delivery of nanoparticles across the blood-brain tumor barrier into malignant glioma cells. J Transl Med 6:1-15. doi:10.1186/1479-5876-6-80
Sau TK, Murphy CJ (2004) Seeded high yield synthesis of short $\mathrm{Au}$ nanorods in aqueous solution. Langmuir 20:6414-6420. doi:10.1021/la049463z

Shukla R, Bansal V, Chaudhary M, Basu A, Bhonde RR, Sastry M (2005) Biocompatibility of gold nanoparticles and their endocytotic fate inside the cellular compartment: a microscopic overview. Langmuir 21:10644-10654. doi: 10.1021/la0513712

Skrabalak SE, Chen JY, Sun YG et al (2008) Gold nanocages: synthesis, properties, and applications. Acc Chem Res 41:1587-1595. doi:10.1021/ar800018v

Sonavane G, Tomoda K, Makino K (2008) Biodistribution of colloidal gold nanoparticles after intravenous administration: effect of particle size. Colloids Surf B 66:274-280. doi:10.1016/j.colsurfb.2008.07.004

Stone JW, Sisco PN, Goldsmith EC, Baxter SC, Murphy CJ (2007) Using gold nanorods to probe cell-induced collagen deformation. Nano Lett 7:116-119. doi:10.1021/ nl062248d

Takahashi H, Niidome Y, Niidome T, Kaneko K, Kawasaki H, Yamada S (2006) Modification of gold nanorods using phospatidylcholine to reduce cytotoxicity. Langmuir 22:2-5. doi:10.1021/la0520029

Tervonen T, Linkov I, Figueira JR, Steevens J, Chappell M, Merad M (2009) Risk-based classification system of nanomaterials. J Nanopart Res 11:757-766. doi:10.1007/ s11051-008-9546-1

Troutman TS, Barton JK, Romanowski M (2008) Biodegradable plasmon resonant nanoshells. Adv Mater 20:26042608. doi:10.1002/adma.200703026

Tsoli M, Kuhn H, Brandau W, Esche H, Schmid G (2005) Cellular uptake and toxicity of $\mathrm{Au}(55)$ clusters. Small 1:841-844. doi:10.1002/smll.200500104

Turner M, Golovko VB, Vaughan OPH et al (2008) Selective oxidation with dioxygen by gold nanoparticle catalysts derived from 55-atom clusters. Nature 454:U31-981. doi: 10.1038/nature07194

Unfried K, Albrecht C, Klotz LO, Von Mikecz A, GretherBeck S, Schins RPF (2007) Cellular responses to nanoparticles: target structures and mechanisms. Nanotoxicology 1:52-71. doi:10.1080/00222930701314932

Verma A, Uzun O, Hu YH et al (2008) Surface-structureregulated cell-membrane penetration by monolayer-protected nanoparticles. Nat Mater 7:588-595. doi:10.1038/ nmat 2202

Vesaratchanon S, Nikolov A, Wasan DT (2007) Sedimentation in nano-colloidal dispersions: effects of collective interactions and particle charge. Adv Colloid Interface Sci 134-35:268-278. doi:10.1016/j.cis.2007.04.026

Villiers CL, Freitas H, Couderc R, Villiers MB, Marche PN (2009) Analysis of the toxicity of gold nanoparticles on the immune system: effect on dendritic cell functions. J Nanopart Res 12:55-60. doi:10.1007/s11051-009-9692-0

Von Maltzahn G, Park JH, Agrawal A et al (2009) Computationally guided photothermal tumor therapy using longcirculating gold nanorod antennas. Cancer Res 69:38923900. doi:10.1158/0008-5472.CAN-08-4242

Weissleder R (2001) A clearer vision for in vivo imaging. Nat Biotechnol 19:316-317. doi:10.1038/86684 
Willets KA, Van Duyne RP (2007) Localized surface plasmon resonance spectroscopy and sensing. Annu Rev Phys Chem 58:267-297. doi:10.1146/annurev.physchem.58. 032806.104607

Yamada KM, Cukierman E (2007) Modeling tissue morphogenesis and cancer in 3D. Cell 130:601-610. doi:10.1016/ j.cell.2007.08.006
Zhang GD, Yang Z, Lu W, Zhang R, Huang Q, Tian M, Li L, Liang D, Li C (2009) Influence of anchoring ligands and particle size on the colloidal stability and in vivo biodistribution of polyethylene glycol-coated gold nanoparticles in tumorxenografted mice. Biomaterials 30:1928-1936. doi:10.1016/j.biomaterials.2008.12.038 